\title{
Personalized medicine in Brazil: a new paradigm, old problems
}

\author{
Claudia Pavani and Guilherme Ary Plonski \\ University of São Paulo, São Paulo, Brazil
}

\begin{abstract}
Purpose - Personalized medicine (PM) encompasses a set of procedures, technologies and medications; the term became more prominent from the 2000s onwards and stems from the mapping of the human genome. The purposes of this study were to analyse the development stage of the process of technological innovation for PM and the obstacles that prevent PM from being adopted in the public health system in Brazil.
\end{abstract}

Design/methodology/approach - As a research method, this paper opts for a case study carried out at the Hospital das Clínicas, which belongs to São Paulo Medical School. In total, 22 in-depth interviews were carried out at the hospital to identify current practices in PM, future prospects and barriers imposed to the adoption of PM technologies in public health.

Findings - Personalized or precision medicine is already a reality for a small portion of the Brazilian population and is gradually gaining ground in public health care. One finding is that such changes are occurring in a disjointed manner in an incomplete and under development health innovation system. The analysis pointed out that the obstacles identified in Brazil are the same as those faced by high-income countries such as regulation, lack of clinical studies and need to adapt clinical studies to PM. They appear in all stages of the innovation cycle, from research to widespread use.

Research limitations/implications - The research method was a case study, so the findings cannot be extrapolated to other contexts. A limited number of professionals were interviewed, their opinions may not reflect those of their organizations.

Originality/value - There are several studies that discuss how health-care systems in high-income countries could incorporate these new technologies, but only a few focuses on low or middle-income countries such as Brazil.

Keywords Public health, Innovation, Personalized medicine

Paper type Research paper

\section{Introduction}

Personalized medicine (PM) involves a set of procedures, technologies and medications; the term became influential during the 2000s. Thus, PM is expected to generate significant benefits for populations. It was propelled by the confluence of two technological revolutions - the mapping of the genome and information and communication technologies (ICTs). This study aims to analyze how this innovation can be absorbed and used in Brazilian public health.

(C) Claudia Pavani and Guilherme Ary Plonski. Published in Innovation and Management Review. Published by Emerald Publishing Limited. This article is published under the Creative Commons Attribution (CC BY 4.0) licence. Anyone may reproduce, distribute, translate and create derivative works of this article (for both commercial and non-commercial purposes), subject to full attribution to the original publication and authors. The full terms of this licence maybe seen at http:// creativecommons.org/licences/by/4.0/legalcode

Funding: This study was financed in part by the Coordenação de Aperfeiçoamento de Pessoal de Nível Superior - Brasil (CAPES).

Received 16 April 2019

Revised 21 July 2020

21 September 2020

Accepted 4 October 2020$$
\text { (1) }
$$ 
INMR

18,4

The research issues that guided our study were:

- at what development stage is the process of technological innovation for PM; and

- what are the obstacles that prevent PM from being adopted in the public health system in Brazil.

As a research strategy, we made use of a case study, identifying the obstacles that affect the public health system in the state of São Paulo. The organization studied was the Hospital das Clínicas (abbreviated as the HC), which belongs to São Paulo Medical School, São Paulo Department of Health (abbreviated as the SES), the National Commission for the Incorporation of Technology in the Public Health System (abbreviated as the Conitec), established national companies, investors and startups. In total, 22 in-depth interviews were carried out with actors from these bodies to identify current practices in PM, the actors' vision for the future and obstacles that hinder the adoption of PM in the public health-care system.

The article is organized as follows. Section 2 describes PM, the context in which it arose, its benefits and limitations. Section 3 introduces information regarding the financing of the Brazilian public health-care system. The research method, conceptual model and case study are covered in Section 4. Sections 5 and 6 present the analysis and our final considerations. Finally, Section 7 indicates the references used in our article.

\section{Personalized medicine}

The idea of PM is nothing new. Any medical treatment essentially is or should be, specific to each individual case. Even though PM took on different meanings and definitions over the past two decades, in this study we define PMas:

[...] the use of combined knowledge (genetic or otherwise) about a person to predict their susceptibility to a disease or response to treatment and, in this way, to improve the health of that person (Redekop \& Mladsi, 2013, p. S4).

Recently, the term "precision medicine" has come to be used in a pharmacogenomic context, which is an area that studies patients' response to medications and treatments in a context of genetic variations. Another concept often encountered in literature is P4 medicine (predictive, preventive, personalized and participative). In scientific and non-scientific literature, these terms are interchangeable.

Medical decisions, practices and drug-based treatments would then be customized in PM: the drug or treatment and the dosage at the right time according to each individual. The basis of PM is the aggregation of populational, genetic and non-genetic data associated with information on the individual. This information ranges from comorbidities, lifestyle, age, use of other medication, patient preferences and socioeconomic and environmental conditions. The individual is part of subpopulations, which are mapped and have their own profiles (Iriart, 2019).

The benefits, limits and promises are numerous. Under the concept of PM, technologies were developed to assist the prevention, diagnosis, treatment and monitoring of disease. They are especially used in the treatment of diseases caused by genetic defects such as rare diseases [1] and cancer and can be applied to chronic diseases and even to the dosage of antibiotics. Diagnostic tests are a fundamental element, as they identify genetic mutations in individuals or tumors. Table 1 illustrates the types of tests, the clinical question that it aims to answer and examples of application. The companion diagnostic test is especially relevant; according to the US Food and Drug Administration (2019), "it is an in vitro medical device, 
which provides essential information on the safe and effective use of a medication or corresponding biological product."

There is recognition that PM could have an important role in public health care. Since 2016, the concept of PPH - precision public health - has been discussed more frequently (Bilkey et al., 2019). Three potential areas of activity have been identified:

- stratification of the population in risk groups according to chronic diseases for the development of prevention strategies, more efficient treatments and reduction of costs;

- primary prevention with the use of triage as a tool used at different levels such as in prenatal counseling, in newborns and in schools, reducing non-transmissible, genetic and metabolic diseases; and

- access to populational genetic (and non-genetic) data, which could assist the tracking of diseases and investigation of outbreaks.

These strategies could also reduce the inequalities found in the health-care system (Bilkey et al., 2019; Boro \& Kishore, 2016; Khoury \& Galea, 2016).

The approaches that criticize PM are broad and cover not only issues related to their foundation but also technical, economic and ethical limitations.

\begin{tabular}{|c|c|c|}
\hline Tests & Clinical question & Examples \\
\hline $\begin{array}{l}\text { Test for disease- } \\
\text { susceptibility }\end{array}$ & $\begin{array}{l}\text { What is the risk of developing a disease } \\
\text { in the future? }\end{array}$ & $\begin{array}{l}\text { People who have a deleterious mutation in the } \\
\text { genes BRCA1 or } 2 \text { are at risk of developing } \\
\text { breast and ovarian cancer }\end{array}$ \\
\hline Prognostic test & What is the patient's prognosis? & $\begin{array}{l}\text { The MammaPrint is a genomic test that } \\
\text { analyzes gene activity in tumor tissue. It } \\
\text { supports the decision for post-surgery } \\
\text { treatment }\end{array}$ \\
\hline Triage & Does the person have the disease? & $\begin{array}{l}\text { Individuals who have a family history of } \\
\text { heterozygotic hypercholesteremia should } \\
\text { adopt healthy lifestyle and habits }\end{array}$ \\
\hline Complementary & What is the recommended treatment? & Only individuals with breast cancer who have \\
\hline diagnostic test - & \multicolumn{2}{|c|}{ Will the patient respond well/badly to thesuper-expression of HER2 respond to } \\
\hline effectiveness & given treatment? & $\begin{array}{l}\text { Trastuzumab monoclonal antibody treatment. } \\
\text { This represents } 15 \text { to } 20 \% \text { of individuals }\end{array}$ \\
\hline $\begin{array}{l}\text { Complementary } \\
\text { diagnostic test- } \\
\text { safety }\end{array}$ & $\begin{array}{l}\text { Will there be adverse reactions to the } \\
\text { medicine? }\end{array}$ & $\begin{array}{l}\text { Carbamazepine is an oral medicine used to } \\
\text { treat epilepsy and bipolar disorder among } \\
\text { others. People who carry the HLA-B*1502 } \\
\text { marker have a high probability of having } \\
\text { bleeding and skin problems }\end{array}$ \\
\hline Monitoring tests & $\begin{array}{l}\text { Should treatment continue, change or } \\
\text { stop? Is other treatment necessary? }\end{array}$ & $\begin{array}{l}\text { Warfarin is a member of a group of } \\
\text { anticoagulants used in the prevention of } \\
\text { thrombosis. The maintenance of the therapy } \\
\text { depends on the CYP2C9 and VKORC1 } \\
\text { genotypes }\end{array}$ \\
\hline $\begin{array}{l}\text { Monitoring and } \\
\text { response to } \\
\text { treatment }\end{array}$ & $\begin{array}{l}\text { How long should the individual take to } \\
\text { respond to treatment? }\end{array}$ & $\begin{array}{l}\text { The deadline for treatment of hepatitis } \mathrm{C} \text { with } \\
\text { PEG interferon alpha and ribavirin depends } \\
\text { on the viral RNA level }\end{array}$ \\
\hline
\end{tabular}

Source: Based on Redekop and Mladsi (2013)

Personalized medicine in Brazil 
INMR

18,4

PM was created in the context of systems biology and advances in ICTs, transdisciplinarity and genetics. Systems biology is the analysis of relations among elements pertaining to a system in response to genetic or environmental disturbances to understand the system or some emerging property of the system. A biological system can understand molecules, cells, organs, individuals or even ecosystems (Weston \& Hood, 2004). The main hypothesis of systems biology is that it is possible to formulate mathematical, graphical or descriptive models of organisms, test them with data obtained from disturbances and subsequently compare them to the model. In each test, the model is reformulated until there is adherence to the experimental data. Systems biology is often criticized due to flaws in the definition of what is a normal and healthy organism (Iriart, 2019) and the impossibility of constructing a model, considering that little is known about the functioning of diseases and organisms.

Diseases are complex and there is evidence that they are related to an association between a multiplicity of genes and some medical conditions such as obesity, hypertension and certain types of cancer (Khoury \& Galea, 2016; Iriart, 2019); often, genetic association plays a smaller role than behavior, lifestyle and social factors. Even in oncology, most cancers are caused by a mixture of genetic abnormalities, which vary according to their original location and across individuals and are strongly influenced by environmental factors.

A pillar of PM, the relationship between genotype and phenotype, created through mathematical and statistical models in large populational databases, still does not provide evidence of better disease prediction in individuals, except in some diseases of genetic origin. An important example comes from studies in mental health, where environmental factors are associated with growth in diseases. This situation occurs intensely in middle and low-income countries. In these countries, rapid urbanization without planned infrastructure causes increases in poverty, environmental challenges and an increase in the prevalence of anxiety, depression and substance abuse (Schumann et al., 2019).

Another discussion is the cost-benefit relationship of health-care investments for society. If the focus is collective and not individual and the objective is the maximization of benefits for collective health, which medical approaches and investments are the most appropriate? Would it not be those that facilitate the generation of social and process innovation seeking to maximize collective benefits, instead of technological innovation, in which the benefit is individual and only for a few? Huge improvement in population health indicators was brought about by advances in socio-economic conditions of the population and actions focused on population groups (Iriart, 2019) such as the implementation of programs of family health, basic sanitation, vaccination or programs of maternal breastfeeding and reduction of tobacco consumption.

Other critics of PM argue that it is just another fad that distracts the population from real problems such as obesity, inadequate education and poverty; it covers up the discussion about the real causes of health-care inequality, which is closely associated with the socioeconomic conditions of the population; and it addresses research funding for a fashionable technology, instead of focusing on more important areas (Olstad \& McIntyre, 2019; Iriart, 2019; Khoury \& Galea, 2016). Finally, critics bring an essential issue for policymakers, which is the sustainability of health-care systems, given the high cost of new technologies (De Negri \& Uziel, 2020).

Lippi and Plebani (2015) point to two technical conditions that enable the transition from traditional to PM: the identification and validation of the biomarkers that can generate medical knowledge and be effective for the incapacity, mortality and morbidity of patients; and the development of robust and reliable tests that identify biological standards associated with most human diseases. Nofziger et al. (2014) underlines the need for carrying out clinical tests to identify genetic variants correlated with the response to medication. 
Once these basic prerequisites are filled, it would be possible to overcome the traditional theory of reference values toward a new concept of individual reference values, allowing for a better prediction of risk for the patient. It is worth highlighting the current use of realworld evidence and data (RWE and RWD, respectively) [2] to monitor safety and adverse events to support regulatory decisions and to design clinical tests in pharmaceutical industries [Food and Drug Administration (FDA), 2020].

Even in high-income countries, there are a few challenges to be overcome. Hamburg and Collins (2010) and Waldman and Terzic (2014) point out the need for systems to reach a level of regulation for genetic tests to protect patients and promote innovation. According to the authors, in the USA, the National Institutes of Health (NIH) and the US Food and Drug Administration (FDA) will invest in translational research and in regulatory science, define better regulatory pathways for the coordinated approval of codeveloped diagnostics and therapeutics, draft risk-based approaches for the adequate evaluation of diagnoses to assess the validity and clinical utility more precisely and make information about the tests available. The European Economic Community implemented regulatory changes aiming at a more suitable environment for the development and adoption of PM. Nofziger et al. (2014), for example, emphasize the following necessary regulatory changes: in biomarkers, which allow the identification of a determined population of patients that could benefit from medication or could have adverse reactions; in biobanks, i.e. procedures that deal with the harmonization clinical laboratory results; pharmacovigilance and harmonization of guidelines in clinical tests; in the protection of personal data of populations and individuals; managing research funding and in discussions of methodologies for the evaluation of PM at the individual level and for health-care systems.

In relation to the genetic mapping of populations, in the first half of the 2010s, the UK, China and the USA began to implement their initiatives. In November 2015, the Brazilian Initiative on Precision Medicine (abbreviated as the BIPMed) was launched by the São Paulo Research Foundation (abbreviated as the FAPESP) to provide clinical and genomic information to the scientific community. Involving translational research, genomics and PM, the proposal introduced by BIPMed aimed at a new level of data integration to improve health care. At the end of 2019, the Ministry of Health [3] (MS) launched the National Platform of Genomes Brazil (Agência Brasil, 2020). According to a lead researcher on the initiative:

Our project seeks to make a general panorama of the Brazilian population as a whole, with a large number of Brazilians, so that we can carry out deeper research on health, the genetics of our society, as well as our origins and how we diverged from these initial population groups.

\section{Who pays the health-care bills in Brazil}

Brazil has a hybrid health-care system. The national health system (abbreviated as the SUS) materializes the health-care policy of the government; through SUS - in the three spheres of the government (federal, state and municipal) - the government guarantees access to healthcare services for an estimated population of 212 million people in September 2020. SUS was instituted by the Federal Constitution of 1988. It is ruled by the principles of universality, equality/equity, decentralization, regionalization/hierarchy of services and participation in the community. It operates from the basic health-care needs such as vaccination, pre-natal, oral health, early detection and treatment of common conditions (diabetes, hypertension, etc.) and supply of essential medication, up to complex high-cost procedures such as hemodialysis and transplantation, treatment of HIV and Hepatitis $\mathrm{C}$ and chemotherapy and
Personalized medicine in Brazil

369 
INMR

18,4

radiotherapy for cancer treatment. Furthermore, SUS carries out actions in public health such as surveillance, epidemic and endemic control for all Brazilians.

Another component of Brazilian health care is supplementary health. Insurers, medical groups, cooperatives and self-governing philanthropic institutions provide insurance and health plans. They are regulated by the state through the National Agency of Supplementary Health-care, linked with the Ministry of Health. Beneficiaries or this modality are $23 \%$ of the population [Agência Nacional de Saúde (ANS), 2019a]; in other words, 47 million people.

There is a direct relationship between citizens and providers, with direct hiring and payments for health services. However, the population attended by supplementary health care can use SUS for expensive, high complexity and/or emergency procedures or have access to certain medications.

An attribute of the Ministry of Health is the incorporation, exclusion or alteration of health-care technologies through SUS, as well as the constitution or alteration of clinical protocols and therapeutical guidelines. It has a collegiate body, the Conitec, whose function is to advise the Ministry of Health on the above-mentioned issues.

In supplementary health, Agência Nacional de Saúde (ANS) (2019b) defines the List of Procedures and Events in Health, which is "[...] the minimal list of compulsory exams, consultations, surgeries and other procedures that health plans should offer to consumers." The updating of this list is accomplished every two years with the participation of a technical group composed of representatives of consumer protection bodies, operators, professional councils, etc. The accomplishment of public consultations is part of the process of updating the list.

Another dimension of "who pays the bill" is the process of innovation funding that "considers two distinct economies, largely separate, the research economy, which is driven by basic research and the business economy, which is driven by the market." (Jackson, 2011, p. 2). Examples of funders in Brazil are the Ministry of Health, the Coordination for the Improvement of Higher Education Personnel (abbreviated as the CAPES) - linked to the Ministry of Education -, the National Innovation Agency (abbreviated as the FINEP) and the National Council for Scientific and Technological Development (abbreviated as the $\mathrm{CNPq}$ - both linked to the Ministry of Science, Technology and Innovation, private foundations and state research foundations (abbreviated as the FAPs). Investors and banks operate in the business economy; some actors such as CNPq, Finep and FAPs also support initiatives in the business economy.

\section{Conceptual model, research method and case study}

There are different types of innovation in the health-care system, namely: pharmaceutical, process, organizational, marketing, equipment and service innovation. The pharmaceutical and equipment mostly adhere to traditional theories of industrial innovation. Organizational, process, marketing and service innovation present some specific dynamics (Greenhalgh et al., 2004; Tigre \& Nascimento, 2015), without a theoretical body as robust as in technological innovation. Despite the different dynamics, one can identify a few interconnections. A new medication will not be broadly adopted if the health-care system does not incorporate it, if it is not prescribed or if it is not used. Then, to be used, it may require innovation in service and process.

Some concepts will be presented and clarified herein to facilitate a better understanding of the research issue. One concept is technology in health which, according to the International Network of Agencies for Health Technology Assessment (INAHTA, 2020) is: 
An intervention developed to prevent, diagnose or treat medical conditions; promote health; allow rehabilitation; or organize the delivery of health-care. The intervention can be a test, device, medicine, vaccine, procedure, program or system.

Another term is Health Technology Assessment (HTA), which according to INAHTA (2020) is:

Is a multidisciplinary process that uses explicit methods to determine the value of health technology at different points in its lifecycle. The purpose is to inform decision-making to promote an equitable, efficient and high-quality health system.

Technology is not neutral, let alone health-care. They evolve over time and their incorporation and use must be understood according to their respective historical contexts of health-care systems in their countries, considering economic and social policies (Novaes \& Soárez, 2015).

Given that the research aim is to analyze the obstacles that prevent the use of new PM technologies in public health, the conceptual model we used is based on the life cycle of health technologies (Figure 1).

In the life cycle of health technologies, the trigger that turns research, an idea or knowledge into innovation depends on its nature, which is very diverse. When approval from a regulating body is necessary such as for pharmaceuticals and medical equipment, it may be seen a dividing line. For unregulated artifacts, there are no such clearly defined frameworks. Examples of this latter category include organizational, process and marketing innovation. Some parallels can be drawn between innovation in the health-care area with entrepreneurship, when an idea evolves and turns into a startup there are purchase intentions for a minimum viable product, pilot customers and/or a business model (Blank, 2013).

After the approval of a regulatory authority for regulated artifacts or the transformation of an idea into a startup, during the initial stages of diffusion the innovation is adopted by small groups, frequently those who were involved in the stage of innovation evaluation. At the same time, there are pressures from interest groups to incorporate the new technology and, in parallel, a search for acceptance from opinion formers such as the scientific community and medical societies (Novaes \& Soárez, 2015). At the stage of incorporation, the

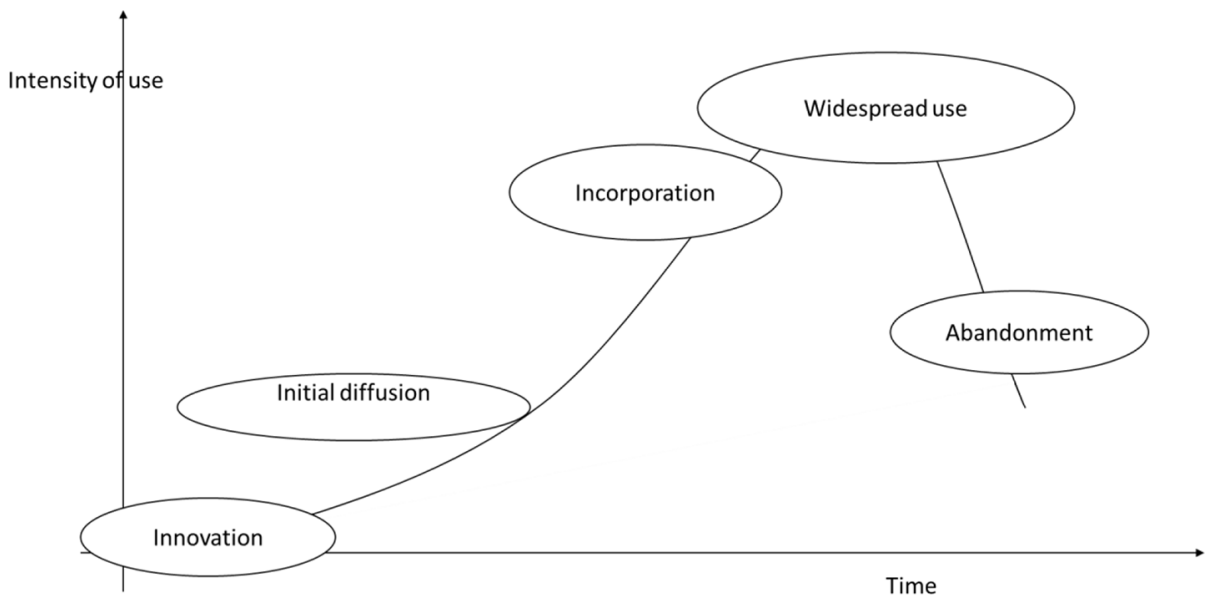

Source: Banta and Luce (1993) cited by Novaes and Soárez (2015, p. 337)
Personalized medicine in Brazil

Figure 1.

Life cycle of health technology and innovation stages 
INMR

18,4

public sector and supplementary health organizations decide which technologies are likely to be paid to the suppliers of health technologies. When incorporated, widespread use of the innovation may occur. At abandonment, there is a substitution of technologies for others. These stages, summarized herein, present nuances and complexities, are sequential and not every research achieves the diffusion level.

The incorporation of health technologies by governments and supplementary health-care organizations in Brazil makes use of practices developed by HTA. The most relevant concept is evidence-based medicine, which seeks:

Scientific evidence about the efficiency, accuracy, effectiveness and safety of a medication, product or procedure, accepted by the competent body for the registration or authorization of use and the comparative economic evaluation of the benefits and costs in relation to the technologies already incorporated, including inpatient, outpatient or hospital care, where applicable. (Law No. $12,401 / 2011$, which relates to therapeutic treatment and the incorporation of health technologies by SUS).

\subsection{Method}

We present herein qualitative research, whose method chosen was a case study that focuses on a subset of the public health innovation ecosystem. We chose this particular matter due to the contemporary and multidisciplinary nature of the theme, the incompleteness and the inadequacy of existing theories for the research issue. As Eisenhardt (1989, pp. 548-549) points out, case studies are suitable for "[... ] new areas of research or areas of research for which existing theories seem inadequate." The first stage was the conduction of bibliographic research, with the identification of the aspects to be mapped and the drafting of the interview script. Afterward, the previous categories were defined. The purpose of the interviews was to identify the actors' knowledge about PM, information about its use, the adherence of PM technologies in the institution at which the interviewees work and obstacles to PM adoption.

Between 2017 and 2018, primary data were collected with actors representing the São Paulo public health ecosystem. In total, 22 professionals [4] were interviewed; 19 belonging to 13 organizations in the public health ecosystem of the state of São Paulo plus three specialists. We used the convenience sampling method followed by a cascade sampling process. The first interviews were conducted with actors with a broader vision of the issue e.g. directors of the University of São Paulo Medical School (abbreviated as the FMUSP), HC and SES, who indicated the professionals dealing with the specific subject (at SES, these professionals were the ones responsible for planning, rare diseases, inputs) and which $\mathrm{HC}$ institutes should be part of the research. The interviews lasted approximately $2 \mathrm{~h}$, guided by a semi-structured script previously sent to all interviewees. The notes were transcribed and compared to identify convergences, divergences, connections and understandings. Additional information was obtained from scientific and non-scientific websites and publications.

In November 2019, the event "Personalized Medicine: a new paradigm in Public Health?" was held at the University of São Paulo's Faculty of Economics, Administration and Accounting. The event was open to the public and organized by the Center for Policy and Technological Management, a support center for research linked to the University's Dean of Research. The debater, director of SES, made several considerations that will be approached herein. The results will be presented over the next subsections. 


\subsection{Hospital das Clinicas and its innovation ecosystem in personalized medicine}

A particularly relevant actor in the health innovation ecosystem is the teaching hospital, which is active in the fields of health care, teaching, research and innovation. This privileged position enables it to provide feedback into the system, incorporating the challenges and knowledge acquired in health care into teaching and research activities. It also fosters collaborations with other science and technology institutions, the productive and the third sector with their respective civil society organizations. Our case study focuses on $\mathrm{HC}$ and a subset of the organizations that interact with it. Created in 1943, the hospital has currently eight institutes; it is the largest tertiary referral hospital in the state of São Paulo (and in Latin America), being responsible for 1.4 million outpatient consultations, 47,000 operations, 14 million laboratory tests, 1 million imaging examinations and 163,000 urgent and emergency care in 2018; all these activities were carried out by 19,000 employees with the availability of 2,500 hospital beds [Hospital das Clínicas da Faculdade de Medicina da Universidade de São Paulo (HCFMUSP), 2019].

HC's innovation ecosystem comprises funders, consolidated companies and startups, regulators, specialists, science and technology institutions, independent researchers and investors.

\section{Analysis}

This work evaluated the stage of development of the technological innovation process for PM and the obstacles that hinder its use in Brazilian public health.

One observes that there are dozens of research projects in progress involving PM disciplines in the HC complex. The Cancer Institute (ICESP), the Heart Institute (INCOR) and the Children Institute ( $\mathrm{ICr}$ ) were the institutes where such practices are most prominent.

At ICESP, the use of PM technologies occurs in three different situations. In standard situations, procedures and drugs incorporated by the SUS are used. New drugs or procedures not yet approved by the National Health Surveillance Agency (abbreviated as the Anvisa) are used for patients who participate in industry-initiated clinical trials. Then, in the third situation, ICESP uses its own budget to test drugs approved by Anvisa, but not yet incorporated by SUS - the decision regarding this testing is made by an internal delegation, known as the Health Technology Assessment Committee. According to the interviewees, PM provides significant advances in cancer treatment, whether for the $5-10 \%$ of hereditary cancer syndromes or for the other 90 $95 \%$ of cancer occurrences. There are proofs of such advances. According to one interviewee, "these technologies are of great importance, considering the aging of the population, which should turn this disease into the main cause of death in Brazil soon." Access to medications and technologies is not a restriction, as there are suppliers in Brazil for medications incorporated by the Ministry of Health. Alternately, the medications are provided by medical trial service contractors.

The ICr, a national reference in child health, brings together 20 pediatric specialties, providing highly complex care to newborns, children and adolescents. It is responsible for the treatment of many children with monogenic diseases with structural abnormalities, that is, with genetic defects, "most diseases caused by a genetic defect are revealed in early life" said an interviewee. Successful innovation in this field was the development of genetic tests with more sensitive techniques, including fluorescence and the multiplex ligation-dependent probe amplification, which detects and validates genomic changes not identified by previously available methods through the G-banding technique used to produce a visible
Personalized medicine in Brazil 
INMR

18,4

karyotype. These more sensitive diagnostic tests were incorporated by the Ministry of Health. The research carried out by researchers from FMUSP, the Federal University of São Paulo and $\mathrm{ICr}$ investigated patients with apparently normal karyotypes and syndromic clinical phenotype. The main objective was to evaluate and adopt new and suitable diagnostic methods to be applied in the public health system in the country, implementing these methods of molecular cytogenetics for the diagnosis of syndromes at the $\mathrm{HC}$ Cytogenomic Medical Laboratory.

INCOR is the Institute specialized in cardiology, pulmonology and cardiac and thoracic surgery. It develops clinical research projects and is involved in a few innovation processes; it uses genomic diagnostic tests in-hospital care. Familial hypercholesterolemia (FH) is currently being investigated using PM, this disease is described by the Brazilian Society of Cardiology as a:

[...] serious disease responsible for $5-10 \%$ of cases of cardiovascular events in people under 50 years old. The risk of an untreated heterozygous $\mathrm{FH}$ carrier developing coronary heart disease or dying reaches $50 \%$ in men and $12 \%$ of women at 50 years of age [...].

It is characterized by high cholesterol levels of low-density lipoproteins (LDL-c), xanthomas and a high risk of early cardiovascular disease (Santos et al., 2015).

The management of $\mathrm{HC}$ has a positive attitude toward the advances of PM developed in Brazil, especially at the University of São Paulo (USP). An example of such attitude is the preliminary interest in using the results of PM research in theranostics [5], under development at the Chemistry Institute of the University [6].

The obstacles to the adoption of PM technologies were analyzed and grouped according to the health system, technology and organization while relating them to the stages of the life cycle of health technologies.

With regard to the health system (Table 2), the statement of an interviewee illustrates the reality of the health system "there are things that precede. The focus today [at SES] is to organize, set up, build the network. Fill the care void.” There is a consensus that in SUS there are some gaps, inefficiencies to be solved and other priorities; in accordance with another interviewee: "We have a new epidemic: diabetes!" Despite acknowledging PM and recognizing its potential benefits, this issue is not part of the interviewees' current concerns or plans because "we would need to have a study that addressed issues such as:

- complexity: infrastructure, processes and teams, considering the isonomy at the federal, state, regional and municipal level;

- waste stemming from non-support of and non-compliance with technical dimensions; and

- low monitoring and accountability. Today the process is bureaucratic and does not identify what really happens."

Some interviewees stated that political will is necessary, as illustrated by the statement "PM is not a government project, there is no prioritization, plan, leadership, political will and support from society."

The process of incorporating technologies emerged in several speeches such as the inadequacy of HTA methods to PM; some interviewees claimed that:

HTA is not adequate for oncology and rare diseases because it needs standardized outcomes, it does not have a sufficient quantity and does not have a clear outcome. The "n" is small and they are treated at referral centers. For example, in the population served by $\mathrm{HC}$, there is a high mutation associated with ovarian cancer. But considering the SUS population, what is the incidence? 
Obstacles - health-care

system characteristics Description

Government plan $\quad$ MP is not a government project; there is no plan or strategy

HTA The HTA methods are unsuitable for PM

HTA is not adequate for oncology and rare diseases because it needs standardized outcomes; it does not have the sufficient quantity and does not have a clear outcome. The " $n$ " is small, and the patients are treated at referral centers

Epidemiological studies The epidemiological studies are insufficient

There must be epidemiological studies (and there must be individual mapping), even though populational studies are not obstacles in the short term

Technology assessment Technology assessment in large-scale use is an obstacle for SUS and supplementary health

There is no panel comparing the different technologies

HTA is a recent area in Brazil, and its lack of activity is a barrier

Human resources

The human resources are insufficient and are not prepared for PM

In October 2017, only 260 geneticists were registered with the Federal Council of

Medicine, concentrated in the southeastern states

Infrastructure

The infrastructure is not prepared for PM. Many of the new medications have dispensing forms that require different physical structures than the ones of current medications

Cost

Regulation

Clinical and genomic information
Technologies are expensive, and the cost of innovation is increasing: the cost grows more than the benefits, compared to preventive methods

The way through which Anvisa monitors the new technologies is different from the way it controlled the previous ones. Technology, production process and quality are different for immunobiological products and gene therapies

The medications must be released by Anvisa; there are not many drugs for rare diseases, and there are only international studies about them

Anvisa and the National Council for Ethics in Research (CONEP) did not recognize studies with few patients as valid. They would have to be multicenter. The degree of certainty is very small, and there are difficulties in obtaining clearer evidence Clinical and genomic information must be on an integrated basis with transparency and confidentiality

A pillar of PM is the access to clinical and genetic information of the population, "we need information from Brazilians, as there are ethnic issues, many different Human Development Indexes, and several different types of Brazil"
Personalized medicine in Brazil

Table 2.

Obstacles to the adoption of personalized medicine characteristics of the health-care system

Therefore, it would be necessary to develop further epidemiological studies to support the assessments. Other obstacles mentioned were high costs, regulation, training the right quantity of human resources and clinical information.

Regarding PM technologies (see Table 3), we found discrepant opinions. On the one hand:

PM is for everything, for diabetes, cancer, adjusting the antibiotic dose and even drug-drug interactions. It is good for prevention, for non-chemical treatments; with the use of algorithms, we will use protein signature to prevent the development of cancer; pharmacogenomics will help us understand metabolism; we will be able to screen for genetic predisposition to cancer. The future is nutrigenomics and its performance in the environment, which is related to epigenetic memory.

On the other hand, there are some limits, as in mental health:

[...] in mental health, we are finding limits. Culture shapes syndromes. An example is a hysteria, which arises at a historical moment and relates to repression and sex. Today it is depression. The relationship between mental illness and genotype is not direct. 
INMR
18,4

Table 3.

Obstacles to the adoption of personalized medicine technological characteristics
Obstacles - technological

characteristics Description

Physicians' culture and skills The “doctor" plays a central role in health. With PM, this role changes, and the patient become more active. Other skills are needed; medical school curricula will have to be revised

Patients' lack of knowledge The patient is uninformed about the potential and reality of PM. They should have a more active role in the future. Patients must be able to give their opinion on new treatments. It is necessary for the patient to clarify his/her lack of knowledge and for the doctor to listen

There are few current clinical protocols involving PM

The typology of diseases will change

Many diseases should be restructured and reclassified, as well as ICD

Research in MP is expensive, and there is a lack of resources for this purpose, either because of government crises, due to the lack of knowledge, or lack of strategy of the funding agencies

Limits of the new technology Some oncology drugs have not yet been identified for some types of tumor Advances in mental illness are below expectations

As one of the interviewees explains:

For some mental illnesses, a relationship has already been established, for example, autism has a 15-20\% correlation with genetics. Schizophrenia, on the other hand, is known to have more than 200 etiologies. Brain circuits are researched and the trend is to combine symptoms (phenotype) with genome and neuroimaging for diagnosis. The secret is not in the syndrome, what caused it was a metabolic disorder. Another complicating factor: the genome is not necessarily fixed; it changes according to the environment. What we did before running out, which was genetics associated with other markers to make the diagnoses. Patients are heterogeneous.

Among the obstacles, some interviewees mentioned the medical culture, patients' lack of access to the acknowledgment of health technologies and the existence of few protocols and research funding.

The obstacles reported by the actors of the ecosystem subset are related to the university hospital characteristics, its teaching-research-science outreach mission and to deficiencies in the innovation ecosystem. Regarding the transformation of research into innovation, the lack of knowledge about market dynamics and lack of researchers' managerial skills to act in innovation processes was mentioned by an interviewee: "what else do I have to do ([...] for my research to reach patients [... .])? I go to congresses, I published the results, I already went to a Conitec meeting."

In relation to the innovation ecosystem, obstacles of different natures were identified, as in relation to strategy:

The national industry has always distributed medicines imported from abroad, then copied the production process. The development of generic drugs was successful. There is no radical innovation. It is related to the original strategy. PM is on the horizon of national companies, but they need to survive. They believe they will find a shortcut.

His current outlook is: "we are learning to do research and development, internalizing activities, assembling teams and designing strategies." Collectively, they seek to maintain an original strategy, considering that PM is a new technological base. They see opportunities in segments abandoned by multinationals. Competencies in productive bioprocesses were also mentioned: "national companies are not prepared to develop biopharmaceuticals, they are just following the multinational industry." Table 4 show the obstacles related to the ecosystem. 
Obstacles - organizations in subset

of the public health ecosystem

Universities and science and technology institutes

Researcher's ability to innovate

Brazilian pharmaceutical companies

Startups
Description

There is no internal organization to avoid repetition of efforts There are duplicated efforts and a lack of knowledge in organizations about PM initiatives

The strategy for PM in universities and science and technology institutions is fragile

Educational and research institutions recognize that their curricula are not suitable for the training of professionals to work with the new technologies

Science and technology institutes do not have a clear strategy to approach PM

There is a gap in the ability to turn research into innovation and bring it to the market

There is an abyss between research and knowledge production and its practical use

National pharmaceutical companies identify the opportunity but are not mobilized

PM startups identify the opportunity but are undermined due to the immaturity of the ecosystem

They are mostly research spin offs, innovative in products, services and/or business models. They recognize that they do not have the necessary assets to act as suppliers to the end customer, as they lack certified physical facilities, brand recognition, financial leverage, distribution channels, working capital, etc.

They resent the lack of interest of the national industry for codevelopments and acquisitions. The business model of similar companies in more developed markets is the acquisition of the startup by more established companies. Although there are agencies and investors in the state of São Paulo, some stages in the innovation process are difficult to finance
Personalized medicine in Brazil

Table 4.

Obstacles to the adoption of personalized medicine organizations in subset of the public health ecosystem

Subsequently, we present the obstacles present throughout the life cycle of health technologies (Table 5).

\section{Final considerations}

Personalized or precision medicine is already a reality for a small portion of the Brazilian population and is gradually gaining ground in public health care. This research exposed part of this process through a case study. One finding is that such changes are occurring in a disjointed manner in an incomplete and under development health innovation system.

The analysis pointed out that the obstacles identified in Brazil are the same as those faced by high-income countries (Hamburg \& Collins, 2010; Waldman \& Terzic, 2014; Nofziger et al., 2014; Lippi \& Plebani, 2015) such as regulation, lack of clinical studies and need to adapt clinical studies to PM. They appear in all stages of the innovation cycle, from research to widespread use.

The use of PM in public health (Bilkey et al., 2019; Boro \& Kishore, 2016; Khoury \& Galea, 2016; Iriart, 2019; Olstad \& McIntyre, 2019) involves cost-benefit analysis (De Negri \& Uziel, 2020), the sustainability of the health system, the disregard for environmental, behavioral, lifestyle and social factors as determinants of health, which is also a finding of our research. 


\begin{tabular}{|c|c|c|}
\hline & & \\
\hline 18,4 & $\begin{array}{l}\text { Stage of the lifecycle in health } \\
\text { technology }\end{array}$ & Obstacles \\
\hline & Research & $\begin{array}{l}\text { Inadequate research funding: higher volumes of resources are needed } \\
\text { Fragile or non-existent strategies of universities and science and technology } \\
\text { institutes for PM }\end{array}$ \\
\hline 378 & Innovation & $\begin{array}{l}\text { Regulations } \\
\text { Gan in researcher skills to transform research into innovation }\end{array}$ \\
\hline & & $\begin{array}{l}\text { Inadequate funding for startups: mechanisms in Brazil are not sufficient and } \\
\text { adequate for the challenges of PM } \\
\text { Open innovation in health care is still incipient. The corporate venture is in } \\
\text { its initial phase } \\
\text { Large national pharmaceutical companies are shyly structuring themselves } \\
\text { to work in PM }\end{array}$ \\
\hline & Initial diffusion & $\begin{array}{l}\text { Doctor's culture } \\
\text { Lack of understanding of technologies by patients } \\
\text { Existence of few clinical protocols }\end{array}$ \\
\hline & Incorporation & Inadequacy of HTA methods \\
\hline Table 5. & & $\begin{array}{l}\text { Insufficient epidemiological studies } \\
\text { No comparison between technologies }\end{array}$ \\
\hline Stage in the life cycle & Widespread use & Insufficient human resources and skills \\
\hline $\begin{array}{l}\text { Of health } \\
\text { technologies and }\end{array}$ & & Inadequate infrastructure \\
\hline obstacles & & $\begin{array}{l}\text { High cost of treatments } \\
\text { No integrated patient information system }\end{array}$ \\
\hline
\end{tabular}

There is a shared view that these technologies are not a panacea (Khoury and Galea, 2016; Iriart, 2019); therefore, in some medical areas the use of PM technologies might not be suitable, for example, in mental health (Schumann et al., 2019).

A notable difference is the absence of a plan and coordinated action at a national and organizational level to deal with the issue and its implications. There are a few exceptions, namely, FAPESP's BIPMed and the National Genome Platform Brazil. In turn, the US government included PM in the bioeconomy, an economic activity that is fueled by research and innovation in the biological sciences (The White House, 2012) [7]. Two aspects that supported its formulation were: recognition of the importance of collaboration in non-traditional research and collaboration between the public and private sectors in the sharing of genetic information.

The dynamics of innovation can feed the productive and research fields while being the basis of new enterprises for new or consolidated companies, involving universities, research centers, innovation environments, investors and service providers. For health system payers, innovations in PM are, among other factors, associated with high costs and prices, therefore restricted by government budgets or the cost equations of supplementary health organizations. On the other hand, one of the aims of PM is to act as a cost reducer such as in the early detection of diseases and in the reduction of hospital admissions (an example could be the expected decrease in hospital admissions due to adverse drug reaction). We presented herein a few complex issues that require studies, reflections and considerations. The ones who are constantly pursuing health benefits for the Brazilian population must devise solutions that overcome tight models and connect past, present and future.

The challenge that the COVID-19 pandemic poses to technologies linked to PM is the subject of current reflection. Why are some individuals more affected than others? Are there genetic causes? Could the genetic mapping of the population associated with other information be a tool to deal with pandemics? It is worth remembering the social impact the pandemic, i.e. the Sars-CoV-2 virus, causes in several countries, with constant social 
isolation, companies and governments changing ways to operate and with alterations in work and production.

This article contributes to the discussion about the multiple dimensions associated with the incorporation of PM in the public health system in the state of São Paulo and, consequently, in Brazil. Advances in this direction, which overcome the limitations resulting from the case study method used herein, will require further studies.
Personalized medicine in Brazil

\section{Notes}

1. Rare diseases, according to the World Health Organization, affect up to 65 in 100,000 individuals. There are around 8,000 rare diseases mapped. It is estimated that around $80 \%$ of these have a genetic origin (the other $20 \%$ have environmental, infectious or immunological causes). The symptoms of people afflicted are diverse because they can be chronic, progressive, degenerative or even incapacitating. The treatments can me medicated or non- medicated (they include, for example, prosthesis, dietary preparations, among others) and many at extremely high cost. (Ministério da Saúde, 2014a).

2. RWD refers to health data from the government collected by computer, cellphone, biosensors, etc. RWE refers to clinical evidence about the use and benefits or potential risks of a medication derived from analysis of RWD.

3. In Portuguese, Ministério da Saúde [MS].

4. The interviews were conducted with the following professionals: at HC: Heart Institute (INCOR), Cancer Institute of the State of São Paulo "Octávio Frias de Oliveira" (ICESP), Children Institute (ICr), General Institute and Cytogenomics Laboratory of the Pathology Division; FMUSP; at the governmental level: SES and Conitec; in the business world: Federation of Industries of São Paulo (FIESP), startups, a pharmaceutical company with national capital and a venture capital investor and three specialists (two oncologists and one linked to mental health). Their positions and functions were of executive and managerial level. Respondents are physicians (14), biologists (4) and engineers/economists/administrators (4).

5. A combination of the words therapeutics and diagnostics.

6. USP is developing theranostics agents and advanced nanomaterials that that enable the simultaneous diagnosis and treatment of diseases by personalized molecular therapy. It involves the incorporation of targeting agents with specific interaction/connection with tumor tissues or parasites, among others.

7. The US objectives to develop the bioeconomy are: to guarantee investments in research and innovation to guarantee the foundations of the future of the bioeconomy; facilitate the transition of bio inventions from research laboratories to the market, especially in translational and regulatory sciences; develop and reform regulations to reduce barriers, increase the speed and predictability of regulatory processes and reduce costs, protecting the environment and human health; update training programs and align academic institutions with student training for the needs of the workforce and identify and support opportunities for developing public-private partnerships and pre-competitive collaborations.

\section{References}

Agência Brasil. (2020). Projeto liderado por brasileira mapeará genoma de 15 mil pessoas. Retrieved from https://agenciabrasil.ebc.com.br/saude/noticia/2019-12/projeto-liderado-porbrasileira-mapeara-genoma-de-15-mil-pessoas

Agência Nacional de Saúde (ANS) (2019a). Agência nacional de saúde suplementar. Retrieved from www.ans. gov.br/aans/noticias-ans/numeros-do-setor/4926-ans-disponibiliza-numeros-de-fevereiro-do-setor 
INMR

18,4

Agência Nacional de Saúde (ANS) (2019b). Agência nacional de saúde suplementar. Retrieved from www.ans.gov.br//aans/index.php/750-central-de-atendimento-o-que-o-seu-plano-deve-cobrir

Banta, H. D., \& Luce, B. R. (1993). Health care technology and its assessment: An international perspective (pp. 1-5), New York, NY: Oxford University Press.

Bilkey, G. A., Burns, B. L., Coles, E. P., Mahede, T., Baynam, G., \& Nowak, K. J. (2019). Optimizing precision medicine for public health. Frontiers in Public Health, 7(42), 1-9. doi: https://oi.org/10.3389/ fpubh.2019.00042.

Blank, S. (2013). Why the lean start-up changes everything. Harvard Business Review, 91(5), 63-72.

Boro, P., \& Kishore, J. (2016). Precision medicine in public health. Int J Preven Curati Comm Med, 2(3\&4), 1-3.

De Negri, F., \& Uziel, D. (2020). O que é medicina de precisão e como ela pode impactar o setor de saúde? Report no. 2557 to the instituto de pesquisa econômica aplicada. Instituto de Pesquisa Econômica Aplicada [IPEA]. Retrieved from http://repositorio.ipea.gov.br/bitstream/11058/9970/1/td\%202557.pdf

Food and Drug Administration (FDA). (2019). Companion diagnostics. Retrieved from https://www.fda. gov/medicaldevices/productsandmedicalprocedures/invitrodiagnostics/ucm407297.htm

Food and Drug Administration (FDA). (2020). Real-world evidence. Retrieved from https://www.fda. gov/science-research/science-and-research-special-topics/real-world-evidence

Eisenhardt, K. M. (1989). Building theories from case study research. Academy of Management Review, 14(4), 532-550. doi: https://doi.org/10.5465/amr.1989.4308385.

Greenhalgh, T., Robert, G., Macfarlane, F., Bate, P., \& Kyriakidou, O. (2004). Diffusion of innovations in service organizations: Systematic review and recommendations. The Milbank Quarterly, 82(4), 581-629. doi: https://doi.org/10.1111/j.0887-378X.2004.00325.x.

Hamburg, M. A., \& Collins, F. S. (2010). The path to personalized medicine. New England Journal of Medicine, 363(4), 301-304. doi: https://doi.org/10.1056/NEJMp1006304.

Hospital das Clínicas da Faculdade de Medicina da Universidade de São Paulo (HCFMUSP) (2019). Relatório de atividades - Resultados da gestão 2015-2018. Retrieved from http://www.hc.fm.usp. br/images/pdf/superintendencia/relatorios/Relatorio_Atividades_HC_2015_2018\%20v2.pdf

International Network of Agencies for Health Technology Assessment (INAHTA) (2020). Retrieved from http://www.inahta.org/

Iriart, J. A. B. (2019). Medicina de precisão/medicina personalizada: Análise crítica dos movimentos de transformação da biomedicina no início do século XXI. Cadernos de Saúde Pública, 35(3), e00153118 doi: https://doi.org/10.1590/0102-311x00153118.

Jackson, D. J. (2011). What is an innovation ecosystem. National Science Foundation, 1(2), 1-13.

Khoury, M. J., \& Galea, S. (2016). Will precision medicine improve population health? JAMA, 316(13), 1357-1358. doi: https://doi.org/10.1001/jama.2016.12260.

Lippi, G., \& Plebani, M. (2015). Personalized medicine: Moving from simple theory to daily practice. Clinical Chemistry and Laboratory Medicine, 53(7), 959-960.

Ministério da Saúde (MS). (2014a). Diretrizes para atenção integral às pessoas com doenças raras no sistema único de saúde. Retrieved from https://portalarquivos2.saude.gov.br/images/pdf/2014/ junho/04/DIRETRIZES-DOENCAS-RARAS.pdf

Ministério da Saúde (MS). (2014b). Procedimentos laboratoriais para diagnóstico de doenças raras associadas a anomalias congênitas na tabela SUS (report no. 109). Retrieved from http://conitec. gov.br/images/Incorporados/DoencasRaras-EixosI-II-III-FINAL.pdf

National Institutes of Health (NIH). (2019). The human genome project. Retrieved from https://www.genome. gov

Nofziger, C., Papaluca, M., Terzic, A., Waldman, S., \& Paulmichl, M. (2014). Policies to aid the adoption of personalized medicine. Nature Reviews Drug Discovery, 13(3), 159-160. doi: https://doi.org/10.1038/ $\operatorname{nrd} 4257$. 
Novaes, H. M. D., \& Soárez, P. C. (2015). Avaliação de tecnologias em saúde: Técnicas, práticas e políticas. In Costa, L., Bahia, C. \& Gadelha, C. (Eds), Saúde, desenvolvimento e inovação, pp. 327358. Editora Fiocruz.

Olstad, D. L., \& McIntyre, L. (2019). Reconceptualising precision public health. BMJ Open, 9(9), 1-9. doi: https://doi.org/10.1136/bmjopen-2019-030279.

Redekop, W. K., \& Mladsi, D. (2013). The faces of personalized medicine: A framework for understanding its meaning and scope. Value in Health, 16(6), S4-S9. doi: https://doi.org/10.1016/j.jval.2013.06.005.

Schumann, G., Benegal, V., Yu, C., Tao, S., Jernigan, T., Heinz, A., .. Calhoun, V. (2019). Precision medicine and global mental health. The Lancet Global Health, 7(1), e32 doi: https://doi.org/ 10.1016/S2214-109X(18)30406-6.

Santos, R. D., Mata, P., \& Stoll, M. (2015). Hipercolesterolemia familiar, Conectfarma Publicações Científicas.

The White House. (2012). National bioeconomy blueprint. Retrieved from https://obamawhitehouse. archives.gov/sites/default/files/microsites/ostp/national_bioeconomy_blueprint_april_2012.pdf

Tigre, P. B., \& Nascimento, C. V. F. (2015). Teorias da inovação e trajetórias tecnológicas na saúde. in Costa, L., Bahia, L. \& Gadelha, C. (Eds), Saúde, desenvolvimento e inovação, pp. 17-40. Editora Fiocruz. I

Waldman, S. A., \& Terzic, A. (2014). Managing the innovation supply chain to maximize personalized medicine. Cinical Pharmacology \& Therapeutics, 95(2), 113-118. doi: https://doi.org/10.1038/ clpt.2013.228.

Weston, A. D., \& Hood, L. (2004). Systems biology, proteomics, and the future of health care: Toward predictive, preventative, and personalized medicine introduction: Paradigm changes in health care. Journal of Proteome Research, 3(2), 179-196. doi: https://doi.org/10.1021/pr0499693.

\section{Corresponding author}

Claudia Pavani can be contacted at: cpavani5@gmail.com

Associate editor: Felipe Mendes Borini

For instructions on how to order reprints of this article, please visit our website: 